\title{
Mathematical pragmatism
}

\section{Stephen Toulmin}

The Nature of Mathematical Knowledge. By Philip Kitcher.

Oxford University Press: 1983. Pp.287. £15, \$25.

IT WAS more than time for a shift of focus in the philosophy of mathematics. With very few exceptions (Henri Poincaré or Hugo Dingler, for example) twentieth-century writers in this field have worked under the shadow of Gottlob Frege; and Frege's classic work, The Foundations of Arithmetic (1884), apparently demolished for good the attempt to give mathematics a basis in our empirical experience. In particular, Frege's denunciations of "the genetic fallacy", and of "psychologism", were part of a larger, Platonizing attack on the whole subject, and they have been understood to rule out any hope of introducing historical and mental factors into the analysis of mathematical concepts and propositions.

Since Frege, there have been few truly radical changes in the subject. For all of his originality, Ludwig Wittgenstein's posthumous Remarks on the Foundations of Mathematics (1967) never wholly emerged from under Frege's shadow. And although Imre Lakatos's early Proofs and Refutations (1963-1964) placed some emphasis on the historical mutability of basic mathematical notions like "validity", "rigour" and "truth", his alliance with Karl Popper led him, later on, to downplay those insights. Instead, he moved toward a more timeless view of the subject matter of mathematics, as part of a distinct "Third World", set apart from all changing physical and mental things.

Although Frege was a contemporary of Ernst Mach, who showed how far the basic concepts of physical theory are the products of human effort over time - so that, as many philosophers of science today would agree, philosophical accounts of scientific concepts need to be historischkritisch dargestellt - the corresponding insight in the philosophy of mathematics has hitherto made little headway. Nowadays, philosophers rarely focus on the empirical roots of mathematical concepts and procedures, because they have set themselves an oversimplified choice: either, they assume, mathematical truths must be based on empirical experience in the present - the view attributed to John Stuart Mill, which Frege demolished so devastatingly - or, in reaction, they deny to mathematics any empirical basis beyond the self evidence of its axioms and, like Frege himself, treat its claims as transhistorical.

Yet a powerful argument can be presented for thinking that these are not the only options. Must our understanding of the procedures and concepts of mathe- matics, and even their "meaning", rest solely on observations and experiences that can be pointed to in the present? Or do they not depend, equally, on those past experiences that led earlier mathematicians to adopt the systems and formalisms they actually did, rather than other systems or formalisms, which were equally consistent and conceivable? This alternative philosophical approach need not, of course, be taken to imply that mathematical statements function as simple reports of past experience. Rather, it asks whether we can fully grasp the intellectual force and scope of mathematical theories and theorems, if we look only at their formal features, in isolation both from the historical contexts in which they took the forms they did, and from the psychological contexts in which children can master them in the present. This richer alternative is one that presses itself on us the more urgently, at a time when philosophers of science have moved so far towards an alliance with historians of scientific thought, and when the developmental studies of L.S. Vygotsky and Jean Piaget have redirected our attention towards the learning of mathematical concepts and procedures.

Philip Kitcher's book, The Nature of Mathematical Knowledge, is a pioneer attempt to give a thorough philosophical account of mathematics from this third, and novel, point of view. As is the case with many such enterprises, the book opens up more issues than it can cover to general satisfaction. Still, it has many striking features. It opens with a dozen pages of introduction, which provide a clear and courageous statement of the central programme of the new approach, and this deserves a critical reading by all philosophers interested in the subject, quite aside from the rest of the text. (For instance, the introduction hints at many connections that the author does not pursue further: e.g. at parallels between his view of mathematics and J.J. Gibson's "ecological realism" as a view of sense perception.) Among other good things, subsequent chapters explore helpfully the relations between the "historical-critical" account of change in natural science that has developed in recent years, and the novel picture of historical change in mathematical concepts and procedures that will have to be built up, if the new approach establishes itself as a new research programme for the philosophy of mathematics.

Professor Kitcher's argument falls into three parts. Four chapters clear away philosophical undergrowth, and prepare the ground for the constructive work which occupies the author in Chapters 5 to 9, while a long final chapter is given over to a careful study of the development of "Analysis" as a formal branch of mathematics. (I first wrote "a branch of pure mathematics", but struck this out, for Professor Kitcher's approach undermines the traditional contrast between pure and applied mathematics. From his point of view, the only distinctions are ones of degree: based on the comparative distances of different mathematical concepts and theorems from the practical contexts and experiences out of which they initially crystallized.)

Recently, debate within the philosophy of mathematics has become rather specialized and inbred: as a result, those not up in the subject may find the opening part of the book obscure. But such readers are urged to turn to Chapter 5 , where much in the constructive exposition of the new position is presented directly and clearly, without reference to current professional controversies. In particular, Professor Kitcher's discussion of the historical character of conceptual change in natural science and mathematics should be read and discussed by many people - working mathematicians and general philosophers, as well as others - who have no particular commitment to one or another of the current rival positions in the philosophy of mathematics.

If this book is in the end somewhat tantalizing, it is for the best of reasons: viz., that the author throws out many more novel ideas and suggestions than he has the space to follow up. Still, at a few points, this gap between promise and achievements affects his argument. To give just one example, his reading of psychology is limited to certain "individualist"' traditions: apart from his passing reference to J.J. Gibson, the other main references are (for example) to J.A. Fodor and Noam Chomsky. Hence, for instance, he treats the warranting of a belief as a "mental process" in the head of an individual thinker, and ignores the alternative view that treats warrants rather as elements within collective procedures of argument that are developed and applied collectively, or "in the public domain".

Minor shortcomings apart, however, this is a valuable and important book. After the careful and thorough criticism of "creationism"' in his earlier book, Abusing Science, it is a pleasure to see Philip Kitcher making such an original contribution to the philosophy of mathematics, and to general philosophy also. All told, it marks him as having one of the freshest and most versatile minds at work in Anglo-American philosophy today.

Stephen Toulmin is a member of the Committee on Social Thought at the University of Chicago. His most recent book is The Return to Cosmology: Postmodern Science and the Theology of Nature (University of California Press, 1983). 